\title{
INFLUENCE OF DIFFERENT RANDOM PATTERN CREATION FORMS ON THE RESULTS OF EXPERIMENTAL MODAL ANALYSIS PERFORMED BY HIGH-SPEED DIGITAL IMAGE CORRELATION
}

\author{
Martin HAGARA*, Martin SCHRÖTTER*, Pavol LENGVARSKÝ* \\ ${ }^{*}$ Faculty of Mechanical Engineering, Department of Applied Mechanics and Mechatronics, Technical University of Košice, \\ Letná 9, 04200 Košice, Slovakia
}

martin.hagara@tuke.sk, martin.schrotter@tuke.sk, pavol.lengvarsky@tuke.sk

\begin{abstract}
In this contribution an influence of random contrast patterns creation on the quality of the obtained results of experimental modal analysis performed by high-speed digital image correlation is described. Three common forms of random pattern creation were investigated. While the first form was presented by the black speckles printed on white matt vinyl foil and bonded on the sample surface, in the second and the third case, respectively, the black speckles were sprayed on white sprayed sample surface or on paint white one. For the purposes of modal parameters estimation in the form of natural frequencies, mode shapes and damping ratios the program called Modan3D, developed in the authors department, was used. The results obtained by Modan3D were compared with the results achieved by system Pulse specialized for vibration analysis.
\end{abstract}

Key words: Digital Image Correlation, Experimental Modal Analysis, Random Pattern, Modan3D

\section{INTRODUCTION}

Three-dimensional digital image correlation is a modern experimental method for investigation of displacement fields and strain fields. It is based on a comparison of digital images captured from at least two stereoscopically located CCD cameras (Fig. 1) among each other and in time, respectively (Trebuňa and Šimčák, 2007; Chen et al., 2013).

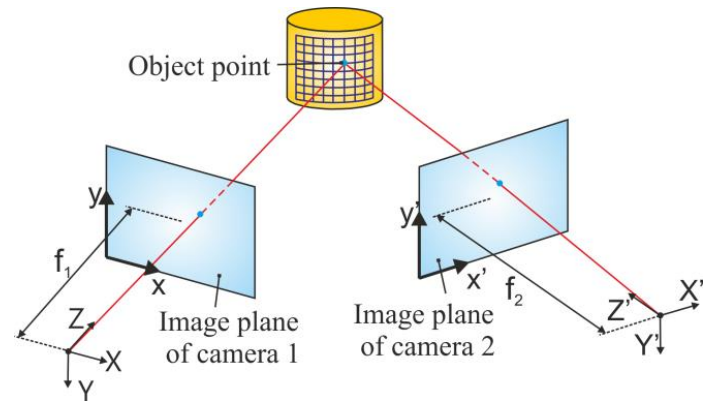

Fig. 1. 3-D digital image correlation system with stereoscopically located CCD cameras

The comparison of images (correlation) is performed on small picture elements called facets, which should be unique. The facets uniqueness is ensured by the creation of random black and white contrast pattern on the investigated object surface. After object loading the displacements in two perpendicular directions $\mathrm{x}$ and $y$ are investigated by the using of pseudo-affine transformations (1), (2) of the nodal points of user defined virtual grid (Herbst et al., 2005) (Fig. 2):

$$
\begin{aligned}
& x_{t}\left(a_{0}, a_{1}, a_{2}, a_{3}, x, y\right)=a_{0}+a_{1} x+a_{2} y+a_{3} x y \\
& y_{t}\left(a_{4}, a_{5}, a_{6}, a_{7}, x, y\right)=a_{4}+a_{5} x+a_{6} y+a_{7} x y
\end{aligned}
$$

where: $x_{t}, y_{t}-$ transformation coordinates, $a_{0}, a_{1}, a_{2}, \ldots, a_{7}-$ transformation parameters, $x, y$ - point coordinates.

Transformation parameters are determined by minimizing the difference between the observed intensity of grey pattern $\mathrm{G}_{2}(\mathrm{x}, \mathrm{y})$ in the deformed image and the intensity of original pattern $G_{1}(x, y)$ with the application of the photogrammetric corrections as follows:

$$
\min _{a_{0}, \ldots, a_{7}, g_{0}, g_{1}} \sum_{x, y}\left\|G_{1}(x, y)-g_{0}-g_{1} G_{2}\left(x_{t}(x, y), y_{t}(x, y)\right)\right\|
$$

where: $g_{0}, g_{1}$ - illumination parameters.

The strain fields are subsequently determined by the analysis of local facets curvatures.

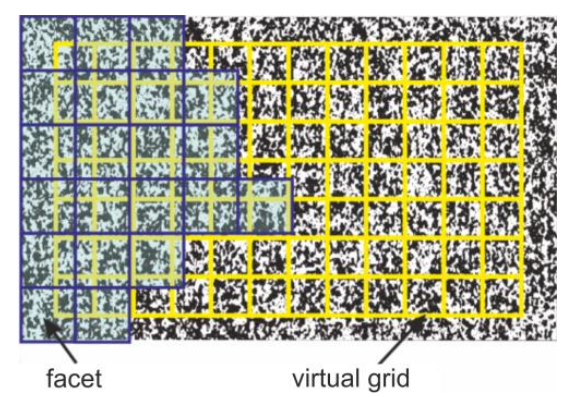

Fig. 2. Object surface with random pattern, facets and virtual grid

In this contribution we investigate the influence of three common forms of random surface pattern creation on the quality of reached results of experimental modal analysis (Madej and Sitek, 2011; Trebuňa et al., 2012) performed by high-speed digital image correlation system Q-450 Dantec Dynamics.

Although the manufacturer declares that this system can be 
used for the purposes of vibration analysis, software Istra4D delivered with Dantec Dynamics correlation systems does not include a module for modal analysis.

For this reason we have created the program called Modan3D serving for experimental (Trebuňa and Hagara, 2014) and operational modal analysis (Trebuňa et al., 2013) interpretation performed by modified high-speed digital image correlation system (Fig. 3).

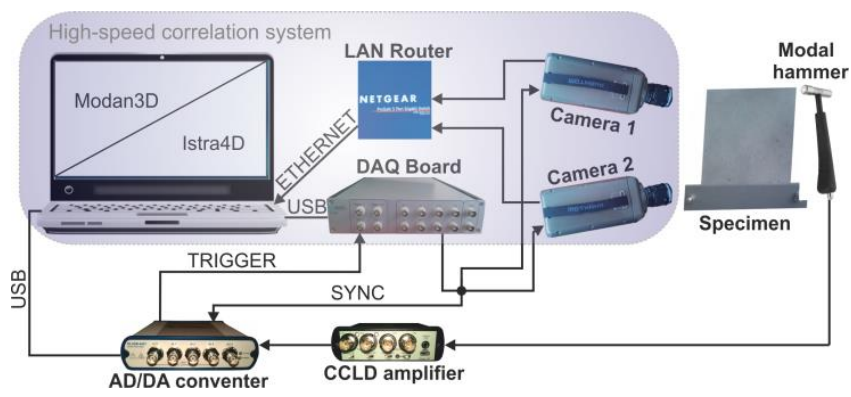

Fig. 3. Modified correlation system for experimental modal analysis

\section{EXPERIMENTAL MODAL ANALYSIS OF A PLANE SPECIMEN PERFORMED BY DIGITAL IMAGE CORRELATION}

The influence of different surface random patterns on the quality of modal parameters estimation was observed on a flat beam made of common construction steel of dimensions depicted in the Fig. 4. The specimen was aside fixed by two screws to a massive console.

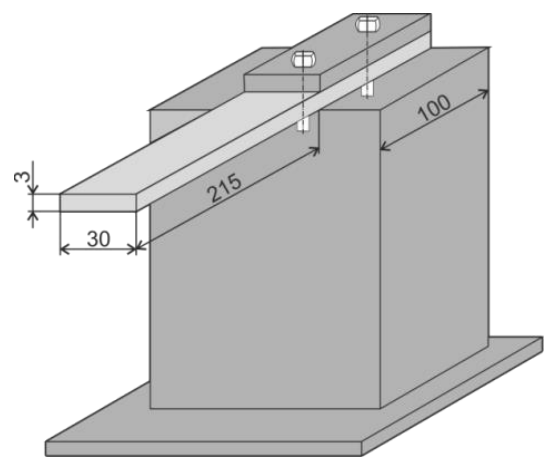

Fig. 4. Dimensions and fixation of the investigated specimen

The creation of the pattern was successively realized by subsequent most common methods:

- Pattern1 - random pattern with maximal speckle diameter of $2 \mathrm{~mm}$ printed on vinyl film (Fig. 5);

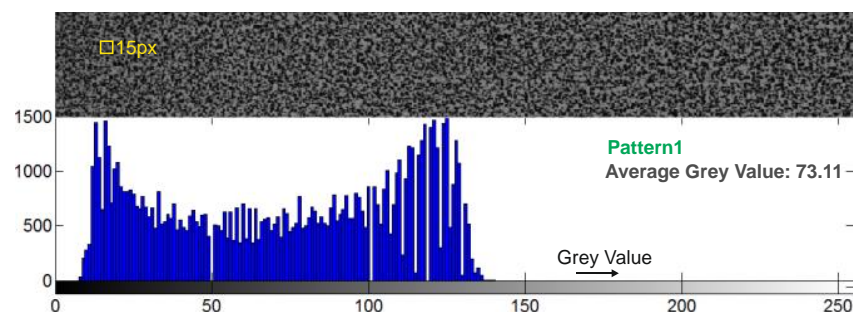

Fig. 5. Investigated Pattern1 with its histogram, average grey value and yellow square representative the facet size used for evaluation
- Pattern2 - random pattern with maximal speckle diameter of $5 \mathrm{~mm}$ sprayed on sprayed white sample surface (Fig. 6);

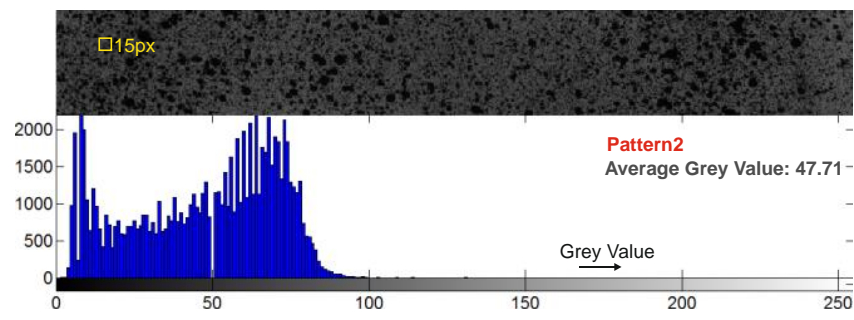

Fig. 6. Investigated Pattern2 with its histogram, average grey value and yellow square representative the facet size used for evaluation

- Pattern3 - random pattern with maximal speckle diameter of $1.5 \mathrm{~mm}$ sprayed on painted white sample surface (Fig. 7).

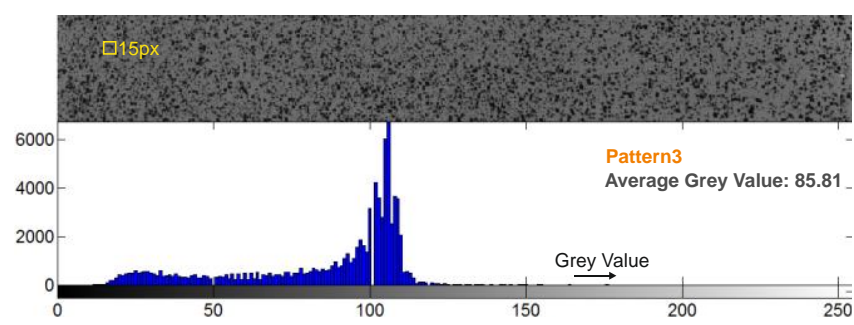

Fig. 7. Investigated Pattern3 with its histogram, average grey value and yellow square representative the facet size used for evaluation

The sampling frequency of high-speed cameras with resolution of $1280 \times 800$ px was set to $5000 \mathrm{fps}$. For the acquisition time of $1 \mathrm{~s}$ the system captured 5000 snapshots. All the measurements were realized by the same light conditions and evaluated by the same settings of correlation parameters. Each measurement was performed three times (Fig. 8). Synchronization between recording of the snapshots and the analog output of the hammer was ensured by the sampling of the synchronization signal of the cameras. Facet size used for evaluation was set to $15 \mathrm{px}$ and the size of virtual grid was $12 \mathrm{px}$.

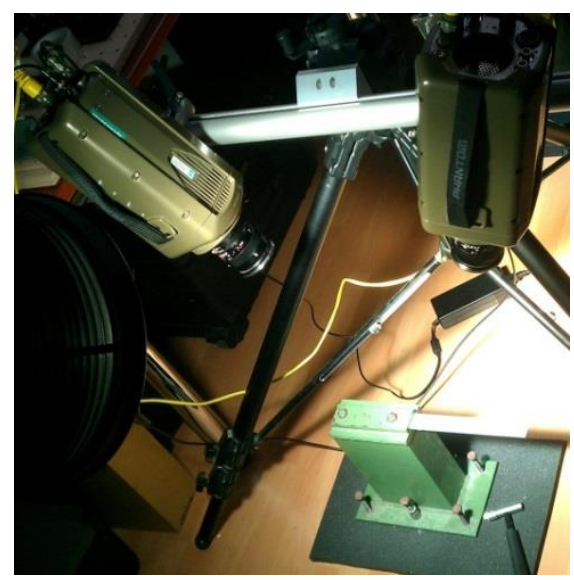

Fig. 8. Cameras configuration with measured specimen

The obtained data exported from the software Istra4D in a form of HDF5 files were subsequently processed in the program Modan3D, into which the files with the data about force impulse from the modal hammer were imported as well. Modan3D 
in accordance to a principal block scheme visible in the Fig. 9 estimated the examined modal parameters and depicted the corresponding mode shapes.

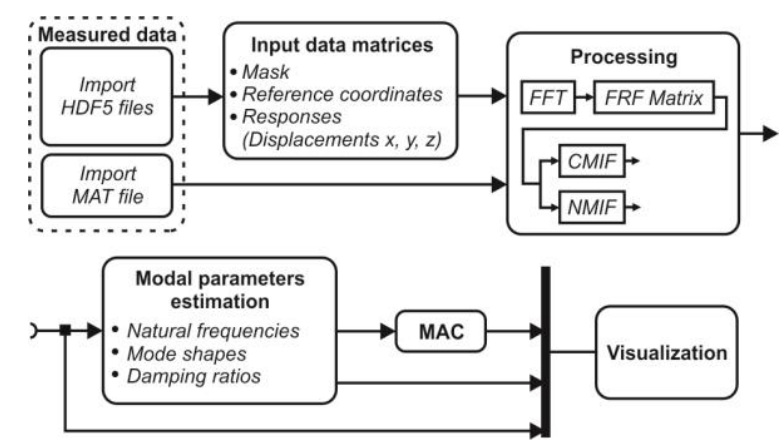

Fig. 9. Algorithm of the program Modan3D

In the figures depicted below it is possible to see the courses of CMIF (Complex Mode Indicator Function) (Fig. 10) and NMIF (Normal Mode Indicator Function) (Fig. 11) (Allemangr and Brown, 2006; Brandt, 2013; Trebuňa et al., 2012,), which elements were determined from the average elements values of the FRFs (Frequency Response Functions) obtained from each of three measurements evaluated by Modan3D.

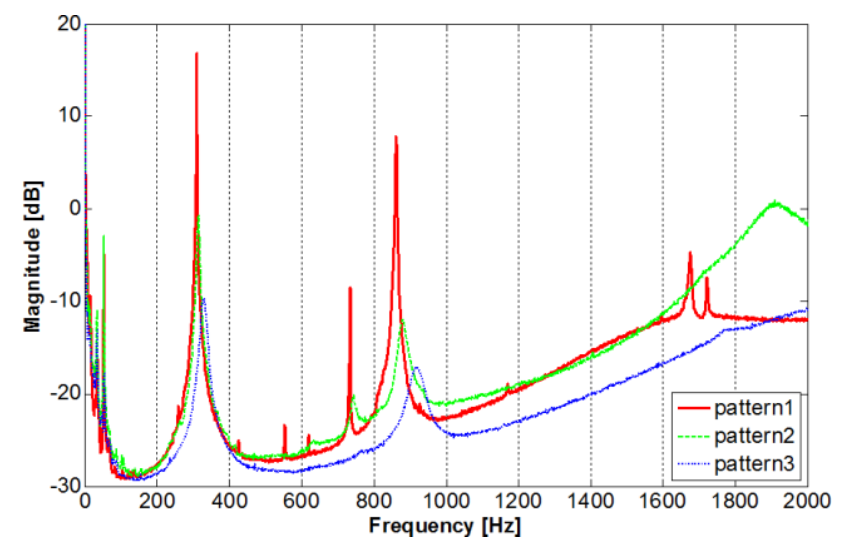

Fig. 10. Complex mode indicator functions obtained by Modan3D

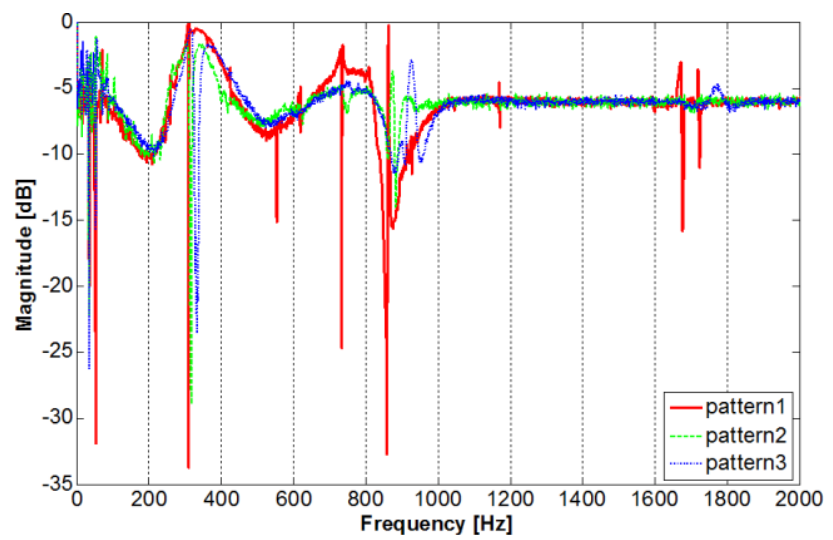

Fig. 11. Normal mode indicator functions obtained by Modan3D

For the purposes of the results verification an experiment with the system Pulse specialized for vibration analysis was done. The response in a form of velocity was recorded in 45 chosen sample surface points by laser-Doppler vibrometer and the excitation was realized in one point with the same modal hammer (Fig.12). The results of the analysis in a form of CMIF can be seen in Fig. 13.

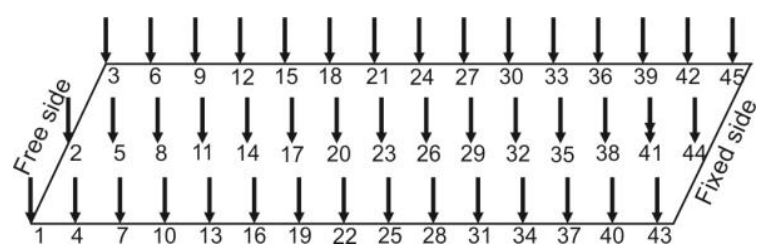

Fig. 12. Forty five measured response points and the point of excitation (point 41)

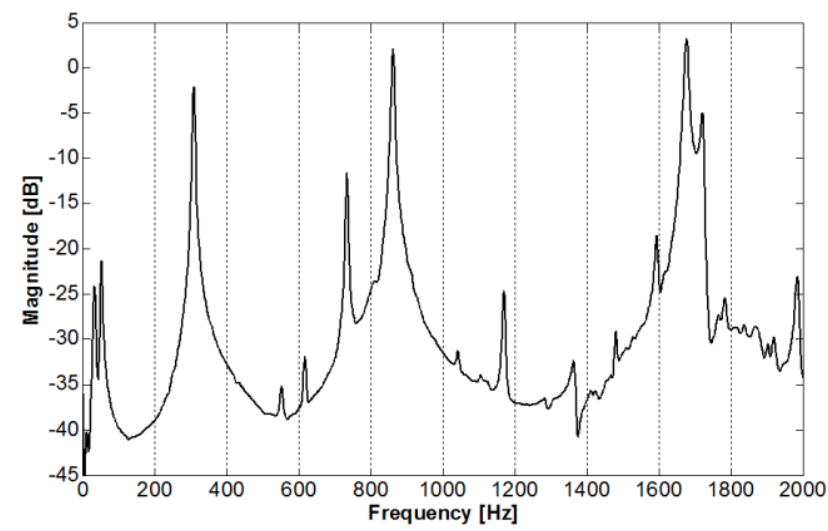

Fig. 13. Complex mode indicator function obtained by Pulse

As the digital correlation system Q-450 sampled the displacements in ca. 3240 nodal grid points and the vibrometer sampled the velocity in 45 points, the experimental results verification consisted only in a comparison of particular natural frequencies and corresponding mode shapes.

In the following tables it is possible to see the amount of natural frequencies obtained by the experimental methods mentioned above and the comparison of damping ratios (Huňady et al. 2012) determined by Modan3D.

Tab. 1. Natural frequencies obtained by Modan3D and Pulse

\begin{tabular}{|c|c|c|c|c|c|}
\hline Method & 1. mode & 2. mode & 3. mode & 4. mode & 5. mode \\
\hline $\begin{array}{c}\text { DIC } \\
\text { Pattern1 }\end{array}$ & $52 \mathrm{~Hz}$ & $310 \mathrm{~Hz}$ & $735 \mathrm{~Hz}$ & $862 \mathrm{~Hz}$ & $1676 \mathrm{~Hz}$ \\
\hline $\begin{array}{c}\text { DIC } \\
\text { Pattern2 }\end{array}$ & $53 \mathrm{~Hz}$ & $314 \mathrm{~Hz}$ & $743 \mathrm{~Hz}$ & $880 \mathrm{~Hz}$ & - \\
\hline $\begin{array}{c}\text { DIC } \\
\text { Pattern3 }\end{array}$ & $55 \mathrm{~Hz}$ & $329 \mathrm{~Hz}$ & - & $920 \mathrm{~Hz}$ & - \\
\hline Pulse & $51 \mathrm{~Hz}$ & $309 \mathrm{~Hz}$ & $735 \mathrm{~Hz}$ & $861 \mathrm{~Hz}$ & $1676 \mathrm{~Hz}$ \\
\hline
\end{tabular}

Tab. 2. Comparison of damping ratios obtained by Modan3D

\begin{tabular}{|c|c|c|c|c|c|}
\hline Method & 1. mode & 2. mode & 3. mode & 4. mode & 5. mode \\
\hline $\begin{array}{c}\text { DIC } \\
\text { Pattern1 }\end{array}$ & 0.0092 & 0.0020 & 0.0010 & 0.0019 & 0.0032 \\
\hline $\begin{array}{c}\text { DIC } \\
\text { Pattern2 }\end{array}$ & 0.0105 & 0.0120 & 0.0158 & 0.0198 & - \\
\hline $\begin{array}{c}\text { DIC } \\
\text { Pattern3 }\end{array}$ & 0.0223 & 0.0202 & - & 0.0205 & - \\
\hline
\end{tabular}


For the comparison we introduce also some mode shapes obtained by program Modan3D (Fig. 14) and system Pulse (Fig. 15).

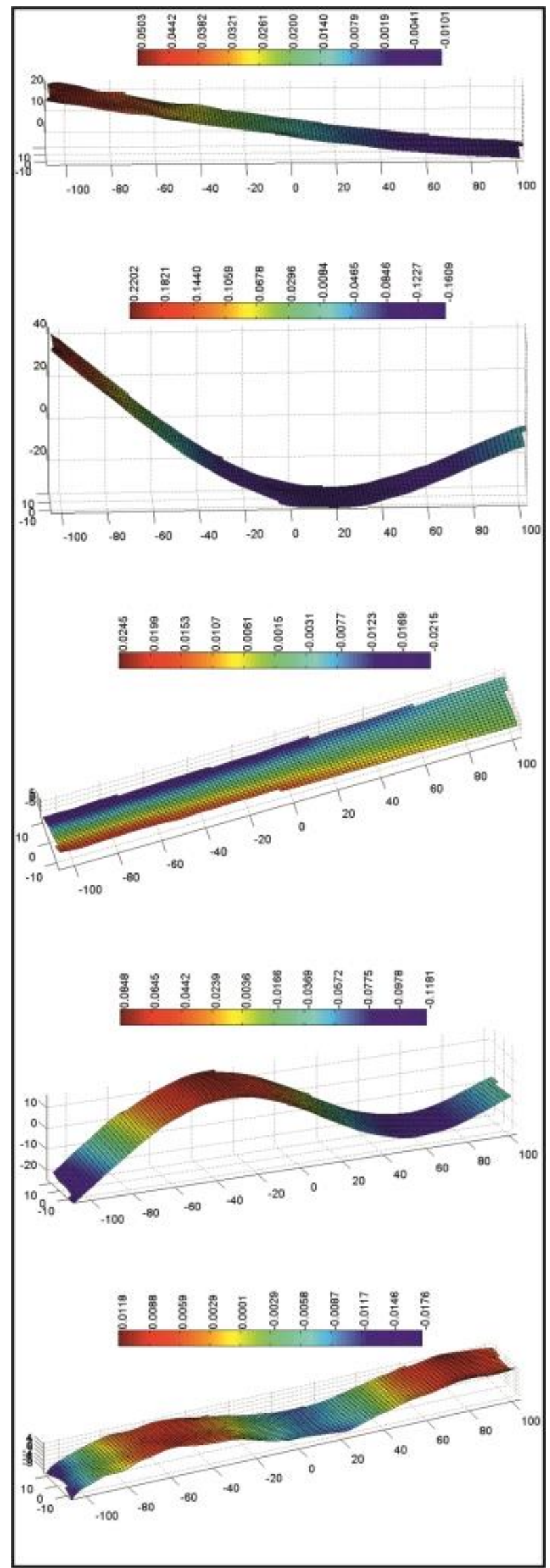

Fig. 14. Mode shapes obtained by program Modan3D

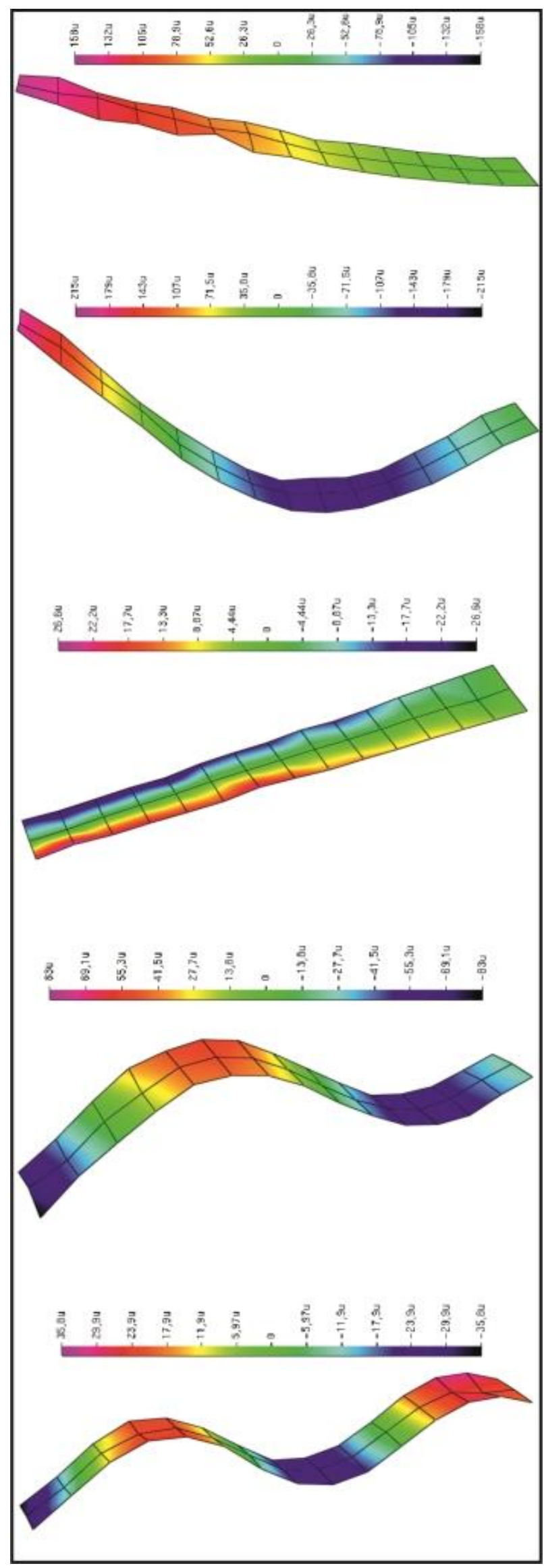

Fig. 15. Mode shapes obtained by system Pulse 


\section{CONCLUSION}

It is useful and time-saving to use the high-speed digital image correlation method as a modern noncontact full-field way for vibration analysis. By the use of the system with two stereoscopically located CCD cameras it is possible to investigate especially flat samples or samples with reasonably curved surface. By the random pattern application it is necessary to take into account its influence on the modal parameters estimation. While the use of vinyl foil with printed pattern bonded on the sample surface does not affect the results, the use of common random pattern creation forms (sprayed or painted pattern) influences the number of excited and evaluated modes and alters the values of natural frequencies as well. We consider the advantages of printed pattern by experimental modal analysis in its homogeneity, creation simplicity, adaptability of maximal speckle radius to the size of investigated samples and last but not least in the minimization of health risk related to the use of dyes.

\section{REFERENCES}

1. Allemangr R. J., Brown L. (2006), A Complete Review of the Complex Mode Indicator Function (CMIF) with Applications, International Conference on Noise and Vibration Engineering, ISMA.

2. Brandt A. (2011), Noise and Vibration Analysis: Signal Analysis and Experimental Procedures, John Wiley \& Sons, Ltd., United Kingdom.

3. Chen F., Chen X., Xie X., Feng X., Yang L. (2013), Full-field 3D measurement using multi-camera digital image correlation system, Optics and Lasers in Engineering, Vol. 51, No. 9, 1044-1052.

4. Herbst C., Splitthof K., Ettemeyer A. (2005), New Features in Digital Image Correlation Techniques, SAE Technical Paper 200501-0897.

5. Huňady R., Hagara M., Schrötter M. (2012), Using High-speed Digital Image Correlation to Determine the Damping Ratio, Procedia Engineering, Vol. 48, 242-249.

6. Madej J., Sitek M (2011), Modal and frequency analysis of electrovibrator kit for different configuration of activators (in Polish), Acta Mechanica et Automatica, Vol. 5, No. 3, 87-90.

7. Trebuňa F., Hagara M. (2014), Experimental modal analysis performed by high-speed digital image correlation system, Measurement: Journal of the International Measurement Confederation, Vol. 50, No. 1, 78-85.

8. Trebuňa F., Huňady R., Bobovský Z., Hagara M. (2013), Results and Experiences from the Application of Digital Image Correlation in Operational Modal Analysis, Acta Polytechnica Hungarica, Vol. 10, No. 5, 159-174.

9. Trebuňa F., Šimčák F. (2007), Handbook of experimental mechanics (in Slovak), TypoPress, Kosice, Slovakia.

10. Trebuňa F., Šimčák F., Huňady R. (2012), Vibration and modal analysis of mechanical systems (in Slovak), Technical University of Kosice, Slovakia.

The work has been accomplished under the projects VEGA 1/0937/12 and KEGA 021TUKE-4/2013. 